\title{
CONFLITOS NO CAMPO, JUDICIALIZAÇÃO E POLÍTICAS PÚBLICAS DE MEDIAÇÃ̃O NO ESTADO DO MARANHÃO
}

\author{
Amanda Cristina de Aquino Costa* \\ Cássius Guimarães Chai*
}

\section{RESUMO}

Sustentado nos princípios norteadores do Direito Agrário, especialmente os princípios da garantia do direito de propriedade e da função social da propriedade, bem como na necessidade da aplicação de métodos de resolução pacífica de conflitos, o presente artigo busca verificar o funcionamento da Comissão Estadual de Prevenção e Combate à Violência no Campo e na Cidade (COECV), com atuação no Estado do Maranhão. Para esse propósito, além do levantamento bibliográfico acerca do tema, realiza-se pesquisa documental com análise da Lei $\mathrm{n}^{\circ} 10.246 / 2015$, responsável por criar a Comissão, relatórios e reportagens acerca da sua atuação na mediação de litígios coletivos rurais pela posse da terra.

Palavras-Chave: Direito Agrário; Direito de propriedade; Função social da propriedade; Mediação; COECV.

\section{CONFLICTS IN THE FIELD, JUDICIALIZATION AND PUBLIC POLICIES OF MEDIATION IN THE STATE OF MARANHÃO}

\begin{abstract}
Based on the guiding principles of the Agrarian Law, especially the principles of the right to property and the social function of property, as well as the need to apply peaceful methods of conflict resolution, this article seeks to verify the functioning of the Comissão Estadual de Prevenção e Combate à Violência no Campo e na Cidade (COECV), operating in the State of Maranhão. For this purpose, in addition to the bibliographical survey on the subject, documentary research is conducted with analysis of Law 10246/2015, responsible for creating the Commission, and reports about its role in mediating rural collective litigation for land tenure.
\end{abstract}

Keywords: Agrarian law; Right to property; Social function of property; Mediation; COECV.

\section{INTRODUÇÃO}

O presente trabalho versa sobre a atuação da Comissão Estadual de Prevenção à

\footnotetext{
* Mestranda em Direito e Instituições do Sistema de Justiça do Programa de Pós-Graduação em Direito da Universidade Federal do Maranhão - PPGDIR/UFMA. Bacharel em Direito - UFMA, Maranhão (Brasil). E-mail: amandaaquinocst@gmail.com.

* Doutor em Direito Constitucional UFMG-CAPES-Cardozo School of Law. Professor Adjunto da Universidade Federal do Maranhão - UFMA, Maranhão (Brasil). E-mail: cassiuschai@gmail.com.
} 
Violência no Campo e na Cidade (COECV), instituída pela Lei no 10.246/2015, como política pública de mediação no que tange aos conflitos possessórios judicializados. Segundo o diploma normativo citado, a Comissão tem atuação em conflitos possessórios coletivos urbanos e rurais, porém, por decisão de recorte metodológico, esta pesquisa terá nestes últimos casos.

O Direito Agrário é ramo jurídico autônomo, tratando acerca dos direitos e obrigações concernentes aos bens imóveis rurais, sua posse e disposição. Por ser essencialmente ligado aos conceitos de posse e propriedade, é possível depreender que dois princípios mantêm significativo grau de importância para suas noções estruturantes: o da garantia do direito de propriedade e da função social da propriedade.

A convivência em sociedade faz com que surja, inevitavelmente, o conflito de interesses que geram insatisfações e tensões sociais. $O$ Estado, por meio da função jurisdicional, detém o poder-dever de compor litígios, acautelar e realizar direitos. Diante do surgimento de demandas, anseios e tendências diversas, houve a necessidade de que processo civil brasileiro passasse por alterações em suas bases. Por esse motivo, foi instituído, pela Lei $\mathrm{n}^{\mathrm{o}}$ 13.105, de 16 de março de 2015, o Novo Código de Processo Civil (NCPC). Novos aspectos do processo começaram a receber um grau maior de prioridade e, assim, ganham destaque a previsão de métodos adequados de resolução de conflitos com foco na construção de soluções não litigiosas.

Por conseguinte, partindo do cenário previamente exposto, o presente artigo busca analisar o funcionamento da Comissão Estadual de Prevenção e Combate à Violência no Campo e na Cidade (COECV), atuante no Estado do Maranhão e vinculada à Secretaria de Estado dos Direitos Humanos e Participação Popular (SEDIHPOP), como mecanismo de solução alternativa de demandas, especialmente pela aplicação do método da mediação.

Deste modo, o problema em tela questiona adequação das atividades desenvolvidas no âmbito do citado mecanismo à legislação pátria pertinente a função social da propriedade rural e ao rito processual civil das ações possessórias rurais, bem como a efetividade da aplicação do métodos de mediação para a construção de soluções adequadas para conflitos no campo e também para possibilitar que o cumprimento de decisões judiciais de reintegração de posse ocorram de forma pacífica.

Para este propósito, inicialmente, discutem-se as origens dos conflitos no campo brasileiro com base na análise do arcabouço principiológico que fundamentam a noção de 
propriedade e da sua função social. Em seguida, analisa-se criticamente o modo como conflitos coletivos pela posse da terra rural para trabalho e moradia são apreciados pelo Poder Judiciário e apresenta as possibilidades abertas pela aplicação dos métodos adequados de resolução de conflito. Por fim, apresenta-se o arcabouço legislativo que fundamenta a COECV e sua função de mecanismo de mediação de conflitos no Estado do Maranhão.

2 CONFLITOS NO CAMPO: a propriedade rural em face da função social

O Direito Agrário, enquanto conjunto de normas que disciplinam as relações do ser humano com a terra, é ramo jurídico dotado de autonomia científica, possuidor de princípios norteadores próprios. Estes representam normas elementares, mandamentos nucleares dos sistemas jurídicos. Servem como base para definir a própria identidade do ramo do Direito analisado, além de constituírem orientação para a interpretação, aplicação e entendimento das próprias normas.

Dessa maneira, uma análise principiológica se faz de elevada relevância para a compreensão dos ramos jurídicos como um todo, partindo de um entendimento pautado nas noções amplas, estruturantes e fundamentais das diversas disciplinas. Acerca do ramo jurídico do Direito Agrário, destaca-se preliminarmente que parte significante dos princípios agrários elencados a nível doutrinário são pautados com esteio nas disposições previstas na Lei $\mathrm{n}^{\circ}$ 4.504/64, o Estatuto da Terra, e na Constituição Federal de 1988.

\subsection{Princípio da garantia do direito de propriedade}

A garantia do direito de propriedade é apresentada por doutrinadores como Márcio Pereira de Andrade (2014), Fabrício Gaspar Rodrigues (2010) e Rafael Costa Freiria e Taisa Cintra Dosso (2015) como um dos princípios constitucionais basilares do ramo do Direito Agrário. Compreende, em síntese, que a propriedade é direito e garantia fundamental do cidadão, estando fundamentado no artigo $5^{\circ}, \mathrm{XXII}$, da CF/88:

Art. $5^{\circ}$ Todos são iguais perante a lei, sem distinção de qualquer natureza, garantindo-se aos brasileiros e aos estrangeiros residentes no País a inviolabilidade do direito à vida, à liberdade, à igualdade, à segurança e à propriedade, nos termos seguintes: [...]

XXII - é garantido o direito de propriedade; [...] (Grifou-se) 
Posteriormente, este princípio é novamente disposto na Lei Maior, em seu artigo 170, II, este integrante da parte relativa à Ordem Econômica e Financeira, conjunto de normas constitucionais que disciplinam as relações monetárias entre os sujeitos, bem como destes com o Estado. Ambas as disposições revelam, de maneira nítida, uma opção política do Estado brasileiro, pois denotam a índole do sistema econômico, fundado na iniciativa privada, mas com percepção da propriedade enquanto meio de proporcionar melhor condição de vida e desenvolvimento, não apenas do proprietário da terra, mas também da sociedade. Neste sentido, o direito à propriedade é um poder atribuído pela própria Constituição e possibilita que o indivíduo possa usar, gozar e dispor da coisa.

Uadi Lammego Bulos (2015, p. 615) evidencia que, a partir do tratamento constitucional dispensado ao direito de propriedade, é possível sentir a autonomia do Estado e os princípios básicos que o regem. Depreende-se, conforme exemplificado pelo autor, se a estrutura estatal é pautada em viés socialista ou capitalista, bem como é viável assimilar outros pormenores jurídicos, econômicos, políticos e sociais evidenciados. É, assim, um direito nodular à fisiologia do Estado e, consequentemente, de toda a base jurídica da sociedade. Seu status constitucional não é porque representa um mero direito individual, de natureza privada, mas uma instituição jurídica que encontra amparo num complexo de normas constitucionais relativas à propriedade.

Os doutrinadores Rafael Costa Freiria e Taisa Cintra Dosso (2015) e Uadi Lammego Bulos (2015) pontuam que o direito à propriedade teve sua origem no campo civilístico, notadamente ligado ao Direito Romano, o qual ajudou a prosperar a concepção de que o direito de propriedade não passava de um atributo da personalidade do indivíduo, um direito natural, associado à concepção de liberdade.

O direito de propriedade, apresentado como princípio no Direito Agrário, foi, aos poucos, distanciando-se de suas bases remotas, consubstanciadas no modelo romanista, por fatores econômicos, políticos, históricos e sociais. O direito de propriedade absoluto foi sendo substituído, aos poucos, por um direito que tem seu exercício condicionado ao cumprimento da sua função social, conforme será melhor disposto posteriormente. A tutela dos interesses coletivos, difusos e individuais homogêneos foram fatores que fizeram com que seu exercício fosse relativizado.

Existe, ainda, o princípio correlato da Melhor Distribuição da Terra, evocado por Márcio Pereira de Andrade (2014), o qual determina que a política de reforma agrária deve 
privilegiar a ocupação da terra por aqueles que querem produzir, sendo de responsabilidade do Estado promover a expropriação das terras improdutivas e destiná-las aos indivíduos que não possuem condições financeiras de adquiri-las.

\subsection{Princípio da função social da propriedade}

Conforme previamente enunciando, o princípio da garantia do direito de propriedade está arquitetado nos artigos $5^{\circ}$, XXII, e 170, II, ambos da Constituição. Todavia, em seguida, nos artigos $5^{\circ}$, XXIII, e 170, III, da Lei Maior, é apresentado o princípio da função social da propriedade, limitador daquele previamente exposto:

Art. $5^{\circ}$ Todos são iguais perante a lei, sem distinção de qualquer natureza, garantindo-se aos brasileiros e aos estrangeiros residentes no País a inviolabilidade do direito à vida, à liberdade, à igualdade, à segurança e à propriedade, nos termos seguintes: [...]

XXII - é garantido o direito de propriedade;

XXIII - a propriedade atenderá a sua função social; [...] (Grifou-se)

De maneira semelhante, na Ordem Econômica e Financeira da Constituição, o atendimento à função social é previsto enquanto princípio geral da atividade econômica, notadamente relacionado à finalidade de concretização da existência digna e da justiça social, expressamente citadas no caput do art. 170.

A função social da propriedade, aponta Uadi Lammego Bulos (2015), prevê a destinação economicamente útil da propriedade, visando a satisfação de interesse público. $\mathrm{O}$ direito de propriedade é assegurado, uma vez que a sua função social seja cumprida, otimizando o uso da propriedade para a comunidade como um todo.

Desta maneira, a propriedade não se configura apenas enquanto direito privado, mas uma instituição voltada à satisfação de uma função social. Caso não atendida a função social da propriedade rural, esta será desapropriada para fins de reforma agrária mediante prévia e justa indenização a ser paga com títulos da dívida agrária, resgatáveis em até vinte anos, a partir do segundo ano de emissão, com previsão no art. 184, da CF/88. Em atendimento também ao princípio da função social da propriedade, são previstas hipóteses de perda da propriedade por usucapião, consoante o art. 191, do referido diploma legal. Ambos os casos exemplificam a relativização do princípio da garantia do direito de propriedade, em atendimento à função social. 
A Constituição Federal de 1988 estabelece, ainda, em seu art. 186, os requisitos que deverão ser atendidos a fim de que seja concretizada a função social da a propriedade rural: aproveitamento racional e adequado; utilização adequada dos recursos naturais disponíveis e preservação do meio ambiente; observância das disposições que regulam as relações de trabalho; e exploração que favoreça o bem-estar dos proprietários e dos trabalhadores.

Rafael Costa Freiria e Taisa Cintra Dosso (2015, p. 22) apresentam o princípio da justiça social como sendo intrinsecamente relacionado à função social da propriedade:

Parcela da doutrina agrarista apresenta como decorrência do princípio da função
social, especialmente no que se refere à observância das disposições que regulam as
relações de trabalho e a exploração agrária que favoreça o bem-estar dos
proprietários e dos trabalhadores, como formadores de outro princípio agrarista. No
caso, o Princípio da Justiça Social, direcionando como finalidade do Direito
Agrário buscar sempre a Justiça Social, por meio da efetivação dos condicionantes
mencionados. (Grifo do original).

Assim, sob esse princípio, devem ser respeitadas as condições mínimas necessárias à subsistência do indivíduo. Visa romper com estruturas injustas, garantindo o acesso à propriedade terra e a dignidade do trabalhador rural, propiciando o aumento da produção. Os doutrinadores apontam, ainda, como decorrente da função social, o denominado princípio ambiental da sustentabilidade ou do desenvolvimento sustentável, haja vista que uma propriedade que respeita a sua função social deverá, necessariamente, ser sustentável, evidenciado que as dimensões econômica, social e ambiental devem ser implementadas de maneira conjunta.

Fica explícito, dessa forma, que os princípios da garantia do direito de propriedade e da função social da propriedade, embora não sejam simetricamente contrários, são constantemente colocados em oposição, haja vista que a propriedade, embora deva ser garantida, está condicionada ao cumprimento de uma função social. Há casos, assim, em que será necessário decidir qual dos dois deverá se sobrepor na situação fática, gerando a composição de litígios.

\subsection{Disposições sobre a posse agrária}

Acerca da temática da posse agrária, dissertam ainda Rafael Costa Freiria e Taisa Cintra Dosso (2015, p. 48) que a análise do seu papel "é essencial para a discussão sobre o cumprimento da função social da propriedade", haja vista que, conforme já exposto no 
presente artigo, a garantia da propriedade está intrinsecamente relacionada ao cumprimento da função social da propriedade, a qual, por sua vez, só poderá ser efetivada mediante o exercício do direito de posse. Nesse sentido, enunciam Silvia Opitz e Oswaldo Opitz (2014, p. 261)

\begin{abstract}
A existência da propriedade, essa relação do homem com a terra, tem sido invariável através dos tempos, de modo que não é com a ficção da "função social" que se vai contra a natureza das coisas. Aceito o direito subjetivo da propriedade consagrado na Constituição (art. $5^{\circ}$ e inc. XXII), não se lhe pode dar uma condição substantiva, pois é mero atributo do indivíduo. A terra, por si só, não tem expressão alguma, porque o título de propriedade é a manifestação da atividade individual nos objetos que cercam o homem e estão sujeitos à sua ação. Quando esta ação é egoísta, impedindo-os de satisfazerem as necessidades humanas dentro da sociedade, a propriedade da terra deixa de ser amparada por não realizar a justiça social. (Grifou-se).
\end{abstract}

Remete-se aqui ao princípio da primazia da utilização da terra, segundo o qual a utilização contínua, efetiva, sem oposição, ou seja, o efetivo labor, assegurando o cumprimento da função social da terra, por certo lapso de tempo, deve se sobrepor à mera titularidade forma da propriedade.

Neste sentido, conforme as disposições de Marés (2010), a necessidade de evitar confusões entre a função da propriedade rural e sua produtividade. Historicamente, a terra é fonte de sustento para a vida humana e não humana de modo que não se pode aceitar a redução simplista de sua função ao critério mercadológico da produção de mercadorias:

\footnotetext{
A terra serve, funciona, tem vida, para dar vida, para reproduzir a vida, não de cada indivíduo isoladamente, mas de todos os seus habitantes, plantas, animais ou humanos. Portanto, sua função é manter a vida nas suas mais diversas formas e em suas mais estranhas e improváveis mudanças. Não importa o que diga o direito, não importa o que diga a lei escrita nas reuniões de representantes dos interesses diversos da sociedade humana. A terra tem a função de prover a vida. É até estranho dizer que a terra tem uma função, ela é a provedora da vida, não por função, por obrigação, mas porque é de sua natureza, da essência de seu ser. (MARÉS, 2010, p. 196).
}

Portanto, a garantia do acesso à terra para moradia e produção diz respeito, inequivocamente, à preservação da vida em suas diversas formas e também da dignidade que permeia a pessoa humana. Esta percepção holística sobre a função social da propriedade rural deve, pois, basear a interpretação das disposições legais.

Ainda, cabe citar que o artigo 1.196 do Código Civil de 2002 (CC) considera possuidor "todo aquele que tem de fato o exercício, pleno ou não, de algum dos poderes inerentes à propriedade". Os direitos inerentes à propriedade, consoante o caput do art. 1.228, compreendem "a faculdade de usar, gozar e dispor da coisa, e o direito de reavê-la do poder de quem quer que injustamente a possua ou detenha". Ressalta-se ainda que o CC trouxe a 
previsão do conceito de função social em seu art. 1288, §1, ao dispor que, ao dispor que "o direito de propriedade deve ser exercido em consonância com as suas finalidades econômicas e sociais $[\ldots] "$... As referidas finalidades fazem clara alusão ao próprio texto Constitucional ao tratar sobre o tema.

3 DO CAMPO AO TRIBUNAL: modos de apreciação de ações possessórias pela Justiça

Como apontado na introdução, coube ao Poder Judiciário o papel prioritário de decisão acerca das disputas sobre direitos de maneira, podendo ser provocado sempre que uma ação significar lesão ou ameaça de lesão a direito por determinação constitucional. No que tange às demandas acerca de conflitos possessórios no campo, nota-se o número cada vez maior de demandas do levadas ao conhecimento da Justiça.

Sobre o crescente número de provocações ao Poder Judiciário, Tate (1995, p. 2837) aponta que este fato é resultado da confluência de diversos fatores, dentre os quais destaca a vivência em uma sociedade democracia, o equilíbrio entre os poderes executivo, legislativo e judiciário, bem como a inefetividade das instituições majoritárias.

No caso específico dos conflitos possessórios no campo não é diferente. Boa parte das ocupações e seus conflitos decorrentes têm origem na ineficiência de ações do Estado em áreas como regularização fundiária, prevenção e combate a fraudes documentais em cartórios de registro de imóveis, reforma agrária e programas habitacionais em áreas urbanas.

Ademais, o crescimento do número de conflitos possessórios judicializados também revela um fortalecimento institucional democrático, uma vez que a busca pela decisão judicial em muitos casos previne ou cria embaraços para uso da violência armada e ilegal para coagir e expulsar ocupantes.

Segundo o Código de Processo Civil, o possuidor tem o direito de ser mantido na posse em caso de turbação e reintegrado em caso de esbulho. As ações possessórias respectivas são dotadas de fungibilidade e, em caso de manejo da ação incorreta, ainda assim o magistrado poderá conhecer o pedido para proteção desde que o autor tenha se desincubido de provar sua posse, a turbação ou o esbulho, a data de ocorrência e a continuação da posse turbada ou a perda da posse esbulhada.

Ressalta-se, por oportuno, que as ações possessórias de manutenção e reintegração não prescindem de demonstração de propriedade. Pelo contrário, por inteligência do parágrafo 
único do artigo 557 do CPC, a alegação de propriedade ou outro direito sobre o bem em disputa não obsta a ação possessória. Ainda, pontua-se a importante previsão de intimação do Ministério Público em casos de ações possessórias que apresentem pólo passivo com grande número de pessoas.

Segundo o artigo 562, CPC, estando a petição inicial devidamente instruída, o juiz deferirá sem ouvir o réu o mandado liminar de manutenção ou reintegração de posse. Em caso de necessidade de justificativa, o magistrado designará audiência de justificação prévia.

Por oportuno, destaca-se previsão de que a tutela de urgência de natureza antecipada, a qual pode ser concedida de maneira liminar ou após justificação prévia, não será concedida quando houver perigo de irreversibilidade da decisão conforme disposto no $\S 3^{\circ}$ do artigo 300 do CPC.

\subsection{Decisões liminares em conflitos possessórios coletivos rurais}

Segundo dados da Comissão Estadual de Prevenção à Violência no Campo e na Cidade, até o ano de $2018^{\dagger}$, chegaram ao conhecimento do mecanismo 121 (cento e vinte e um) casos de conflitos possessórios judicializados identificados como coletivos e localizados em áreas de zonas rurais em situações processuais diversas com predominância de decisões judiciais de caráter liminar.

$\mathrm{Na}$ época do levantamento, 89 (oitenta e nove) dos casos apresentavam decisão favorável à reintegração com requisição de força policial para auxiliar no cumprimento do mandado judicial, dos quais 58 (cinquenta e oito) casos eram oriundos de decisões liminares. Este número corresponde a $65,16 \%$ das ações descritas.

Sabe-se que a proteção ágil da posse é medida fundamental para a garantia do direito do autor quando demonstrados os pressupostos objetivos para a concessão da proteção legal. Entretanto, a concessão indiscriminada de medidas liminares em caso de conflito possessório coletivo pode confrontar diretamente a vedação de tutela de urgência de natureza antecipada quando há perigo de irreversibilidade:

A proteção processual da posse tem a celeridade como um de seus traços característicos, notadamente no âmbito das medidas liminares cabíveis em cada caso. A função da decisão liminar é oferecer uma resposta rápida ao autor, e pode ser

\footnotetext{
† Dados obtidos mediante solicitação de informação formulada perante a Secretaria de Estado de Direitos Humanos e Participação Popular.
} 
concedida se a ocupação ocorreu dentro de "ano e dia" (CPC art. 924) sem a necessidade de oitiva da parte contrária (CPC, art. 928). Aqui é que a sensibilidade agrarista, como se verá, parece ter um importante campo de atuação - na avaliação cautelosa dos termos nos quais a ação possessória será admitida bem como dos elementos com base nos quais a resposta liminar irá se materializar. (DANTAS, 2013, p. 469).

De acordo com o excerto acima, Dantas (2013, p. 480) afirma que, no caso dos conflitos possessórios, a tutela liminar se reveste de efetiva tutela antecipada, uma vez que o seu cumprimento com a retirada dos ocupantes e o desfazimento de plantações e benfeitorias dificilmente poderá ser revertida. Para o autor, resta esvaziado o conteúdo do conflito e cria grande dificuldade para a garantia dos direitos dos ocupantes caso a decisão liminar seja reformada em sede de sentença.

Na mesma linha, ao tratar sobre a vedação de tutela antecipada em face da possível irreversibilidade, Teori Albino Zavascki (2009, p. 147) nos diz que:

No particular, o dispositivo observa estritamente o princípio da salvaguarda do
núcleo essencial: antecipar irreversivelmente seria antecipar a própria vitória
definitiva do autor, sem assegurar ao réu o exercício do seu direito fundamental de
se defender, exercício esse que, ante a irreversibilidade da situação de fato, tornar-
se-ia absolutamente inútil, como inútil seria, nestes casos, o prosseguimento do
próprio processo. (Grifo do original)

Neste sentido, pontua-se que medida liminar em casos de conflitos possessórios deve ser tratada com a devida cautela para fins de evitar os perigos da irreversibilidade e considerando também o impacto social da decisão que, nestes casos específicos, pode deixar famílias desabrigadas e sem terra para trabalho ou reprodução de suas práticas tradicionais.

\subsection{Métodos Adequados de Resolução de Conflitos e o Processo Civil}

Enuncia o art. $5^{\circ}$ do Código de Processo Civil (CPC) que "aquele que de qualquer forma participa do processo deve comportar-se de acordo com a boa-fé”. A partes do processo devem estar comprometidas com o seu resultado, agindo sempre com lealdade e em busca de uma solução coerente para o conflito. Para Ada Pellegrini (2009), o processo é um instrumento posto à disposição das partes como forma de eliminar conflitos e obter respostas às pretensões, gerando uma pacificação geral na sociedade e proporcionando a atuação correta do direito.

\footnotetext{
${ }^{\ddagger}$ Os artigos citados no texto são do Código de Processo Civil de 1973 e, no CPC atual, correspondem aos artigos 558 e 562 respectivamente.
} 
O princípio da cooperação exprime relevante grau de similitude e aproximação com o da boa-fé. $\mathrm{O}$ art. $6^{\circ}$ do $\mathrm{CPC}$ traz que "todos os sujeitos do processo devem cooperar entre si para que se obtenha, em tempo razoável, decisão de mérito justa e efetiva", de modo que o processo representaria o produto da atividade cooperativa triangular. Dessa forma, as partes envolvidas no processo e os agentes do poder judiciário devem buscar comprometimento com os valores do processo constitucionalizado, evitando a imposição de entraves desnecessários. Há, inclusive, previsão de sanções pecuniárias para as partes que agirem de má-fé, criando embaraços à efetivação dos provimentos judiciais. Sobre o princípio, dispõe Elpídio Donizetti (2016, p. 42):

Diante desta nova realidade, torna-se necessário renovar mentalidades com o intuito de afastar o individualismo do processo, de modo que o papel de cada um dos operadores do direito seja o de cooperar com boa-fé numa eficiente administração da justiça. O processo deve, pois, ser um diálogo entre as partes e o juiz, e não necessariamente um combate ou um jogo de impulso genérico.

O Código de Processo Civil de 2015, em diversos momentos, traz a busca concreta pela conciliação entre as partes conflitantes, buscando a resolução dos interesses distintos de maneira amigável. Inclusive, conforme seu art. 334, quando a petição inicial preencher os requisitos essenciais e não for o caso de improcedência liminar do pedido, o juiz deverá designar audiência de conciliação ou de mediação. Se ambas as partes manifestarem, expressamente, desinteresse na composição consensual ou quando não se admitir a autocomposição, a audiência não será realizada, conforme o $\S 4^{\circ}$. Todavia, caso seja manifestado o interesse de uma das partes, consoante disposição do $\S 8^{\circ}$, o não comparecimento injustificado do autor ou do réu à audiência de conciliação é considerado ato atentatório à dignidade da justiça, fato que será sancionado com multa.

No caso específico dos conflitos possessórios coletivos, o artigo 565 do CPC e seus parágrafos, trazem previsão de realização de audiência de mediação com participação do Ministério Público e dos órgãos responsáveis pela política agrária e urbana da União, do Estado ou do Distrito Federal ou do Município, bem como da Defensoria Pública quando houver parte hipossuficiente.

A partir dessa faceta, surge a temática dos meios adequados de resolução de conflitos ou de pacificação social, entendidos enquanto procedimentos não jurisdicionais de resolução de demandas. Assegura o doutrinador Elpídio Donizetti (2016, p. 124) a seguinte proposição: 
A tutela jurisdicional não constitui o único meio de eliminação dos conflitos. Na verdade, a jurisdição é a ultima ratio, a última trincheira na tentativa de pacificação social; fora daquelas hipóteses em que, pela natureza da ação material ou por exigência legal, se fizer necessário o provimento jurisdicional, a juridição só atuará quando estritamente necessário. (Grifo do original)

Os meios adequados mais usuais são os seguintes: a autotutela, a mediação, a conciliação e o julgamento por órgãos administrativos. Para o presente artigo, será abordada, de maneira pormenorizada, apenas o método da mediação.

A mediação é técnica de estímulo à autocomposição, na qual as partes interessadas, com o auxílio de um terceiro (mediador) imparcial, tentam construir um acordo a fim de chegar a uma solução não litigiosa. Preleciona Elpídio Donizetti (2016, p. 125) que "a decisão caberá às partes, jamais ao mediador", representando este um instrumento de aproximação dos litigantes, objetivando primariamente debater o conflito, sendo o acordo apenas uma das consequências. Ao mediador não cabe propor uma solução, mas viabilizar, mediante um levantamento dos conflitos, que as partes envolvidas possam chegar a um consenso.

Destaca-se que, conforme entendimento de Vezulla (2006), o procedimento de mediação de conflitos pode ser usado na abordagem dos conflitos interpessoais, pautado na informalidade, no diálogo, na cooperação e no respeito entre os participantes, representando procedimento privado e voluntário, coordenado por um terceiro capacitado. $\mathrm{O}$ autor compara o trabalho do mediador com o do fruticultor que, visando obter as melhores frutas, não se preocupa por elas, mas sim pelas árvores e plantas que as produzem.

Por fim, a Lei 13.140, de 26 de junho de 2015, trata sobre a sobre a mediação entre particulares como meio de solução de controvérsias e sobre a autocomposição de conflitos no âmbito da administração pública. No art. 21 e seguintes, trata-se especificamente acerca da mediação extrajudicial, que ocorrerá por meio de convite para iniciar o procedimento, o qual poderá ser feito por qualquer meio de comunicação e deverá estipular o escopo proposto para a negociação, a data e o local da primeira reunião. Prevê ainda o art. $9^{\circ}$ que qualquer pessoa capaz que tenha a confiança das partes e seja capacitada para fazer mediação poderá funcionar como mediador extrajudicial.

\section{A ATUAÇÃo da COMISSÃo ESTAdUAL DE PREVENÇÃo À VIOLÊNCIA NO CAMPO E NA CIDADE}


A Comissão Estadual de Prevenção e Combate à Violência no Campo e na Cidade (COECV), com atuação no Estado do Maranhão, foi criada em 29 de maio de 2015, por meio da Lei $n^{\circ} 10.246$, e, conforme o art. $1^{\circ}, \S 3^{\circ}$, do referido diploma legal, é vinculada à Secretaria de Estado dos Direitos Humanos e Participação Popular (SEDIHPOP). O objetivo primordial da Comissão, previsto em seu Regimento Interno, aprovado pela portaria $\mathrm{n}^{\mathrm{o}} 95$ GAB/SEDIHPOP, seria o de "mediar os conflitos no campo e na cidade, atuando de forma preventiva para a não ocorrência de conflitos".

Além das disposições da Lei $\mathrm{n}^{\circ} 10.246 / 2015$, os trabalhos da COECV são disciplinados pelo Decreto Estadual nº 31.048/2015 e do Regimento Interno instituído por meio da Portaria n. 95/2015 - GAB/SEDIHPOP. Ademais, constituem-se como importantes instrumentos da Comissão, o Provimento no 08/2019 da Corregedoria Geral de Justiça e o Manual de Diretrizes Nacionais para Execução de Mandados Judiciais de Reintegração de Posse Coletiva editado pelo extinto Departamento de Ouvidoria Agrária e Mediação de Conflitos do Ministério do Desenvolvimento Agrário.

Dentre as atribuições legais da COECV, está a de se manifestar sobre os estudos de situação produzidos pela Polícia Militar para o cumprimento de decisões judiciais que envolvem ações possessórias (art. $1^{\circ}$ ) e sugerir medidas para assegurar que, no cumprimento das decisões judiciais, sejam respeitados os direitos humanos dos envolvidos em conflitos fundiários e agrários (art. $2^{\circ}$ ). Desta forma, a Comissão preocupa-se em dar efetividade às decisões judiciais, zelando pela garantia do direito de propriedade, combatendo as ocupações especulatórias e resguardando os direitos humanos das famílias ameaçadas de despejo.

Por sua vez, o caráter de atuação enquanto entidade de mediação e apaziguadora de conflitos também está expressamente previsto nas atribuições da COECV no art. $2^{\circ}$ da Lei $\mathrm{n}^{\circ} 10.246 / 2015$, as quais são reproduzidas de maneira otimizada no art. $3^{\circ}$ do Regimento Interno, parcialmente disposto adiante:

[...] II - desenvolver estudos, projetos e ações coordenadas com vistas a prevenir, combater e erradicar a violência no campo e na cidade, sem prejuízo da utilização de outros meios de prevenção e controle que possam vir a ser exercidos;

III - avaliar as medidas necessárias a serem adotadas em ações possessórias coletivas e reivindicatórias, inclusive instando o Ministério Público, o Poder Judiciário e outros órgãos do Sistema de Justiça, a observarem os provimentos e normas regulamentares expedidas pelo Conselho Nacional de Justiça, pela Corregedoria Geral de Justiça do Maranhão e Ouvidoria Agraria Nacional, que tratem sobre litígios agrários fundiários e conflitos por moradia;

IV - sugerir medidas para agilizar o andamento dos processos administrativos e judiciais referentes à regularização fundiária urbana e rural dos sujeitos e grupos 
especificados no caput do artigo $1^{\circ}$;

$\mathrm{V}$ - sugerir medidas para assegurar que, no cumprimento das decisões judiciais, sejam respeitados os direitos humanos e sociais dos envolvidos em conflitos fundiários e agrários;

VI - estimular o diálogo e a negociação entre os órgãos governamentais, a sociedade civil e partes interessadas, com o objetivo de alcançar soluções pacíficas nos conflitos fundiários e agrários; [...]. (Grifou-se).

Com base no excerto acima, destaca-se também a atribuição de atuar no fortalecimento das ações públicas de regularização fundiária, ponto fundamental quando considerado que a insegurança sobre a propriedade da terra é uma das grandes causadoras de conflitos no campo.

Ademais, conforme relatado no decorrer deste item, nota-se que a finalidade principal da Comissão é garantir que o cumprimento de mandados judiciais de reintegração ou manutenção de posse em conflitos coletivos seja cumprido sem violações de direitos humanos . Para tanto, o mecanismo atua prioritariamente no diálogo com a Polícia Militar.

Isto se dá, pois, ações violentas no campo frequentemente são ensejadas pela atuação da força policial do estado, mediante requisição do poder judiciário, uma vez que conflitos pela posse coletiva de áreas, tanto urbanas quanto rurais, devido à grande extensão dos territórios e concentração de inúmeras famílias nas áreas litigiosas, costumam demandar o uso de força policial para o cumprimento das decisões judiciais de reintegração de posse.

\subsection{Modos de atuação da Comissão}

Segundo os incisos do artigo $7^{\circ}$ do Regimento Interno da Comissão, em sua atuação para evitar e mediar conflitos decorrentes de mandados de reintegração de posse expedidos pelo Poder Judiciário, a COECV atuará prioritariamente em conflitos pela posse coletiva de área urbanas e rurais onde há famílias e trabalhadores utilizando a terra para morar ou cultivar de maneira efetiva, de modo que os casos individuais estão fora do escopo de atuação da Comissão.

Por conseguinte, os casos identificados como individuais são encaminhados ao Comando-Geral da Polícia Militar informando que não há óbice à disponibilização de força policial para auxiliar no cumprimento da decisão judicial de reintegração de posse, por não haver medidas de mediação aplicáveis. Ressalva-se, por oportuno, que casos individuais que envolvam possibilidade de grave violação de direitos humanos têm o condão de atrair 
excepcionalmente os trabalhos da COECV.

Encontram-se, ainda, no bojo da atuação desta Comissão os casos que envolvem comunidades tradicionais e os territórios tradicionalmente ocupados por estas, em ocupações antigas e habituais de qualquer tipo. Ademais, a Comissão tem desenvolvido trabalho em casos com lideranças, comunidades e trabalhadores rurais ameaçados em decorrência de conflitos pela posse da terra, a fins de evitar violações de direitos humanos, mortes no campo e atentados à integridade física, ainda que não haja ação de reintegração de posse judicializada.

Ainda, segundo a previsão do $\S 5^{\circ}$ do artigo $7^{\circ}$, são excluídas da apreciação da COECV ocupações situadas em áreas de preservação ambiental (reserva legal, áreas de preservação permanente, entre outras), projetos de assentamento criados em órgãos fundiários e áreas públicas destinadas à execução de obras e serviços públicos. Esta ressalva deve-se à sobreposição de direitos difusos e transindividuais a um meio ambiente equilibrado e a boa prestação de serviços públicos, para o pleno exercício da cidadania, sobre as comunidades que ocupam as referidas áreas.

Deve-se, pois, ressaltar que, conforme o disposto no artigo 10 do referido regimento, ainda que se encontrem dentro do escopo de atuação da Comissão, caso seja verificado o esgotamento das propostas de mediação cabíveis no âmbito da COECV, os casos devem ser encaminhados ao Comando-Geral da Polícia Militar informando que o cumprimento às determinações do Poder Judiciário deve ocorrer com o uso exclusivo dos meios proporcionais indispensáveis à execução da medida, para fins de evitar violações dos direitos humanos das pessoas envolvidas.

A composição atual da Comissão apresenta participação da Secretaria de Estado dos Direitos Humanos e Participação Popular (SEDIHPOP), Secretaria de Estado de Segurança Pública - SSP, Secretaria de Estado das Cidades (SECID), Secretaria de Estado da Agricultura e Pecuária (SAGRIMA), Instituto de Terras do Estado do Maranhão (ITERMA), Comando Geral da Polícia Militar do Maranhão, Defensoria Pública do Estado do Maranhão e quatro integrantes da Sociedade Civil, sendo eles atualmente: União Por Moradia Popular, Sociedade Maranhense de Direitos Humanos, Federação dos Trabalhadores e Trabalhadores na Agricultura do Maranhão e Comissão Pastoral da Terra. Além destes, participam como convidados a Superintendência Regional do INCRA, a Defensoria Pública da União, a Secretaria de Estado de Igualdade Racial, o Ministério Público do Estado do Maranhão e o 
Tribunal de Justiça do Estado do Maranhão.

Consoante informação disposta no site da SEDIHPOP, a Comissão:

[...] atua prioritariamente em conflitos pela posse coletiva de áreas urbanas e rurais, garantindo os direitos humanos de todos os envolvidos. Para prevenir a violência, a COECV desenvolve um trabalho com as lideranças, comunidades e trabalhadores rurais ameaçados por conta dos conflitos pela posse da terra em questão, evitando situações de violação dos direitos humanos, mortes no campo e atentados à integridade física dos envolvidos. (MARANHÃO, 2017).

A atuação da COECV enquanto não apenas mediadora de litígios fundiários, mas também na área de prevenção e combate de conflitos, visando a eliminação da violência no campo e na cidade, possui importância particular no contexto maranhense. Conforme dados colhidos pela Comissão Pastoral da Terra (CPT NACIONAL, 2017), o Estado do Maranhão liderou, no ano de 2017, o ranking de conflitos no campo, posição que ocupa há seis anos.

Cabe destacar que, no início de 2015, preliminarmente à atuação da COECV, o Estado do Maranhão apresentava uma defasagem de mais de 296 processos com decisões judiciais de reintegração de posse ainda não cumpridas conforme informações gerais sobre a atuação do mecanismo disponíveis no site da SEDIHPOP:

Em 2015, havia 296 requisições de força policial para cumprimento de ordens judiciais de ações possessórias. Desde então, foram discutidos em reunião 238 casos, que motivaram a expedição de ofícios, realização de visitas, reuniões com órgãos do poder público e designação de audiências de composição entre as partes. Até dezembro de 2016, foram concluídas as apreciações de 169 casos, onde foram realizados os devidos procedimentos de mediação e articulações para resguardar os direitos de todos os envolvidos, inclusive evitando que famílias vulneráveis em todo território maranhense restassem em situação de rua após a execução da ordem judicial, incluindo crianças, adolescentes, mulheres grávidas, idosos e pessoas com deficiência. Atualmente, 264 casos estão sob análise da Comissão, sendo 204 coletivos e 60 não identificados devido à ausência de estudo de situação. Comparativamente, apesar do grande número de decisões judiciais que diariamente chegam à Coordenação da COECV, houve uma redução do passivo de ordens judiciais não cumpridas do início de 2015 até o final de 2016. (MARANHÃO, 2018).

Pelos motivos previamente expostos, a COECV foi imputada de balizar o cumprimento de ações judiciais mediante força policial, conforme indica a redação do art. 10 do Regimento Interno: “esgotados os procedimentos pela COECV acima apontados e frustrada a execução da medida judicial mediante conciliação, a Força Policial deverá cumprir as determinações do Poder Judiciário, com uso exclusivo dos meios proporcionais e indispensáveis à execução da medida". A força policial, assim, será utilizada apenas em caráter subsidiário, demonstrada e indispensabilidade.

Pontua-se que, além da função de prevenção e mediação de conflito, a previsão legal e a atuação da COECV têm o condão de conferir uma dinâmica administrativa definida 
em lei ao cumprimento das ordens judiciais em ações possessórias, por meio do desenvolvimento de medidas mediação e/ou outras pertinentes, de modo a conferir moralidade ao atendimento das requisições judiciais de disponibilização de força policial para cumprimento de mandados de reintegração de posse.

Depreende-se, dessa maneira, que resta evidenciado, em panorama regulatório e legal, o caráter da COECV enquanto mecanismo mediador de litígios, caracterizado pela busca da resolução de demandas por meio de um viés pacifista, combatendo e prevenindo a violência agrária. Os dados sobre a intervenção da Comissão permitem inferir que o tratamento anteriormente concedido pelo Estado ao cumprimento de ações de reintegração de posses coletivas não atendia a nenhuma perspectiva de resolução adequada de conflitos e cumprimento não violento do mandado judicial.

No âmbito do Direito Agrário, a adoção de métodos de resolução adequada de conflitos representa não apenas que será evitada a judicialização do caso concreto, mas também significa a própria preservação da vida e da integridade física das partes envolvidas quando do cumprimento de mandados judiciais de reintegração de posse em áreas coletivas, uma vez que, conforme já demonstrado, conflitos fundiários, especialmente os de viés agrário, frequentemente resultam em situações violentas para os litigantes.

\section{CONSIDERAÇÕES FINAIS}

O Direito Agrário, dotado de princípios norteadores próprios, tem suas concepções amplamente fundamentadas consoante a incidência de dois princípios: o da garantia do direito de propriedade e o da função social da propriedade, ambos de decorrentes da Constituição Federal de 1988. Por aquele, originado no ramo cível, está compreendida a ideia de que a propriedade é direito e garantia fundamental do cidadão, integrante da Ordem Econômica e Financeira. O segundo, por sua vez, prevê a destinação economicamente útil da propriedade, visando a otimizando do uso da propriedade, mediante a satisfação de interesse público, relativizando o primeiro. Embora estes princípios não sejam contrários, são constantemente colocados em oposição.

O Código de Processo Civil veio em busca concreta da conciliação entre as partes conflitantes, mediante a resolução dos interesses distintos de maneira adequada para ambas, 
sendo que os meios adequados de resolução de conflitos ou de pacificação social foram previstos no CPC enquanto estratégias não jurisdicionais de resolução de demandas. A mediação é uma abordagem de resolução de litígios pautada na informalidade e no diálogo, por meio do auxílio de um mediador imparcial, a qual pode ocorrer tanto no âmbito judicial quanto em espaços extrajudiciais. Destaca-se, pois, a possibilidade de que o Poder Executivo atue e promova processos de mediação voltados para a pacificação social.

Assim, a estruturação da Comissão Estadual de Combate à Violência no Campo e na Cidade com a tarefa de mediar os conflitos no campo e na cidade e atuar de forma preventiva no desenvolvimento e articulação de políticas públicas que reduzam a ocorrência de conflitos se mostra adequada à legislação pátria pertinente à função social da propriedade rural e ao rito processual civil referente à proteção da posse rural. Deste modo, tem-se que a COECV serve ao propósito de dar celeridade, eficiência e moralidade à disponibilização de força policial para cumprimento de decisões judiciais em ações possessórias, em plena consonância com os princípios constitucionais que regem a ação da Administração Pública.

Ademais, a existência do citado mecanismo se mostra relevante e imprescindível, uma vez que o Estado do Maranhão ocupa os primeiros lugares do ranking de conflitos no campo elaborado pela CTP. Neste sentido, para além de garantir que o cumprimento das decisões judiciais de reintegração de posse ocorra de maneira não violenta, a Comissão também atua na promoção do diálogo entre as partes envolvidas no conflito e no envolvimento dos órgãos fundiários responsáveis, da municipalidade e dos demais poderes, para a construção de soluções mais adequadas considerando a complexidade de direitos fundamentais e interesses envolvidos em conflitos coletivos pela posse rural.

Portanto, considerando que nas atribuições da Comissão, firmadas em texto legal, é reiterado o compromisso de utilização de meios de prevenção e controle adequados e que esta realidade foi verificada na prática dos trabalhos desenvolvidos no âmbito do mecanismo, afirma-se que a aplicação de práticas de mediação se mostra como método idôneo para a construção de soluções adequadas para conflitos no campo e também para possibilitar que o cumprimento de decisões judiciais de reintegração de posse ocorram de forma pacífica.

Por oportuno, ressalta-se que a presente avaliação não se debruçou sobre casos específicos trabalhados pela Comissão, pois não se pretendeu esgotar todas as nuances do presente tema nesta breve exposição. Deste modo, surgem novos questionamentos acerca da atuação da Comissão, a avaliação das comunidades que tiveram seus processos apreciados no 
âmbito do mecanismo e a própria repercussão desta política pública no âmbito do Poder Judiciário, problemas estes que devem ensejar novos estudos e novas abordagens.

\section{REFERÊNCIAS}

ANDRADE, Márcio Pereira de. Direito Agrário: coleção leis especiais. 2. ed. Curitiba: Editora Juspodivm, 2014.

BRASIL. Constituição (1988). Presidência da República. Casa Civil. Subchefia para Assuntos Jurídicos. Constituição da República Federativa do Brasil de 1988. Disponível em: <http://www.planalto.gov.br/ccivil_03/constituicao/constituicao.htm>. Acesso em: 08 set. 2018 .

. Presidência da República. Casa Civil. Subchefia para Assuntos Jurídicos. Lei no 10.406, de 10 de janeiro de 2002. Institui o Código Civil. Disponível em: < http://www.planalto.gov.br/ccivil_03/leis/2002/110406.htm>. Acesso em: 08 set. 2018.

Presidência da República. Casa Civil. Subchefia para Assuntos Jurídicos. Lei no 13.105, de 16 de março de 2015. Código de Processo Civil. Disponível em: <http://www.planalto.gov.br/ccivil_03/_Ato2015-2018/2015/Lei/L13105.htm>. Acesso em: 08 set. 2018.

Presidência da República. Casa Civil. Subchefia para Assuntos Jurídicos. Lei no 13.140, de 26 de junho de 2015. Dispõe sobre a mediação entre particulares como meio de solução de controvérsias e sobre a autocomposição de conflitos no âmbito da administração pública; altera a Lei no 9.469, de 10 de julho de 1997, e o Decreto no 70.235, de 6 de março de 1972; e revoga o $\$ 2$ o do art. 6o da Lei no 9.469, de 10 de julho de 1997. Disponível em: <http://www.planalto.gov.br/ccivil_03/_ato2015-2018/2015/lei/L13140.htm>. Acesso em: 08 set. 2018.

BULOS, Uadi Lammêgo. Curso de Direito Constitucional. 9. ed. São Paulo: Saraiva, 2015.

CINTRA, Antonio Carlos; DINAMARCO, Candido Rangel; GRINOVER, Ada Pellegrini. Teoria Geral do Processo. 25 ed. São Paulo: Malheiros Ed., 2009. 384 p.

CPT NACIONAL. Conflitos no campo - Brasil 2017. Goiânia, 2017.

DANTAS, Marcus Eduardo de Carvalho. Função social na tutela possessória em conflitos fundiários. Rev. direito GV, São Paulo , v. 9, n. 2, p. 465-488, Dec. 2013 . Disponível em: $<$ http://www.scielo.br/scielo.php?script=sci_arttext\&pid=S1808-

24322013000200004\&lng=en\&nrm=iso>. Acesso: 11 Mar. 2019.

DONIZETTI, Elpídio. Curso didático de direito processual civil. 19. ed. São Paulo: Atlas, 2016. 
FREIRIA, Rafael Costa; DOSSO, Taisa Cintra. Direito Agrário. In: GARCIA, Leonardo de Medeiros (Coorden.). Coleção sinopses para concursos. v. 15. Salvador: Editora JusPODIVM, 2016.

MARANHÃO. Assembleia Legislativa. Diretoria Legislativa. Lei $\mathbf{n}^{\mathbf{0}} \mathbf{1 0 . 2 4 6}$, de 29 de maio de 2015. Dispõe sobre a criação da Comissão Estadual de Prevenção à Violência no Campo e na Cidade COECV e dá outras providências. Disponível em:

<http://arquivos.al.ma.leg.br:8080/ged/legislacao/LEI_10246>. Acesso em: 09 set. 2018.

Comissão do Estado media conflitos de reintegração de posse para prevenir violência no campo e na cidade. Disponível em:

$<$ http://www.sedihpop.ma.gov.br/2017/03/21/comissao-do-estado-media-conflitos-dereintegracao-de-posse-para-prevenir-violencia-no-campo-e-na-cidade/>. Acesso em: 09 set. 2018.

Secretaria de Estado dos Direitos Humanos e Participação Popular. Portaria no 95 , de 15 de abril de 2016. Aprova o Regimento Interno que dispõe sobre o funcionamento da Comissão Estadual de Prevenção à Violência no Campo e na Cidade (COECV). Disponível em: <http://www.stc.ma.gov.br/legisla-documento/?id=4200>. Acesso em: 09 set. 2018.

MARÉS, Carlos Frederico. A função social da propriedade. In: SONDA, C.;

TRAUCZYNSKI, S. C. (Org). Reforma agrária e meio ambiente: teoria e prática no estado do Paraná. Curitiba: ITCG, 2010. Disponível em: < http://www.itcg.pr.gov.br/arquivos/File/LIVRO_REFORMA_AGRARIA_E_MEIO_AMBIE NTE/PARTE_3_1_CARLOS_MARES.pdf>. Acesso em: 10 out. 2018.

OPITZ, Silvia C. B.; OPITZ, Oswaldo. Curso completo de direito agrário. 8. ed. São Paulo: Saraiva, 2014.

RODRIGUES, Fabrício Gaspar. Direito Agrário. 2. ed. Salvador: Editora JusPODIVM, 2010.

TATE, Chester Neal. Why the expansion of judicial power?. In: TATE, C. N.; VALLINDER, T. (Eds.). The Global Expansion of Judicial Power. New York/ London: New York University Press, 1995.

VEZULLA, Juan Carlos. A mediação de conflitos com adolescentes autores de atos infracionais. Florianópolis: Universidade Federal de Santa Catarina, 2004. Disponível em: $<$ https://repositorio.ufsc.br/bitstream/handle/123456789/86868/212771.pdf?sequence=1 $>$. Acesso em: 09 set. 2018.

ZAVASCKI, Teori Albino. Antecipação da Tutela. 7. ed. São Paulo: Saraiva, 2009. 